\title{
Association between heavy metal and metalloid levels in topsoil and cancer mortality in Spain
}

\author{
Olivier Núñez ${ }^{1,2}$ • Pablo Fernández-Navarro ${ }^{1,2}$ - Iván Martín-Méndez ${ }^{3}$. \\ Alejandro Bel-Lan ${ }^{3}$ • Juan F. Locutura Rupérez ${ }^{3}$ • Gonzalo López-Abente ${ }^{1,2}$
}

Received: 26 September 2016 / Accepted: 5 January 2017 / Published online: 20 January 2017

(C) The Author(s) 2017. This article is published with open access at Springerlink.com

\begin{abstract}
Spatio-temporal cancer mortality studies in Spain have revealed patterns for some tumours which display a distribution that is similar across the sexes and persists over time. Such characteristics would be common to tumours that shared risk factors, including the geochemical composition of the soil. The aim of this study was to assess the possible association between heavy metal and metalloid levels in topsoil (upper soil horizon) and cancer mortality in mainland Spain. Ecological cancer mortality study at a municipal level, covering 861,440 cancer deaths (27 different tumour locations) in 7917 Spanish mainland towns, from 1999 to 2008. The elements included in this analysis were $\mathrm{Al}, \mathrm{As}, \mathrm{Cd}, \mathrm{Cr}$, $\mathrm{Cu}, \mathrm{Fe}, \mathrm{Mn}, \mathrm{Ni}, \mathrm{Pb}$ and $\mathrm{Zn}$. Topsoil levels (partial extraction) were determined by ICP-MS at 13,317 sampling points. For the analysis, the data on the topsoil composition have been transformed by the centred logratio (clr-transformation). Principal factor
\end{abstract}

The original publication contains a mistake. Values in the first row of Table 2 should be: Buccal cavity and pharynx F1 1.0311 .0091 .0541 .059 1.0231 .095

Responsible editor: Philippe Garrigues

Electronic supplementary material The online version of this article (doi:10.1007/s11356-017-8418-6) contains supplementary material, which is available to authorized users.

Gonzalo López-Abente

glabente@isciii.es

1 Environmental and Cancer Epidemiology Unit, National Centre for Epidemiology, Carlos III Institute of Health, Avda. Monforte de Lemos 5, 28029 Madrid, Spain

2 Consortium for Biomedical Research in Epidemiology and Public Health (CIBER en Epidemiología y Salud Pública - CIBERESP), Madrid, Spain

3 Department of Geochemistry and Mineral Resources, Spanish Geological and Mining Institute (Instituto Geológico y Minero de España/IGME), Ríos Rosas, 23, 28003 Madrid, Spain analysis was performed to obtain independent latent factors for the transformed variables. To estimate the effect of heavy metal levels in topsoil composition on mortality, we fitted Besag, York and Mollié models, which included each town's factor scores as the explanatory variable. Integrated Nested Laplace Approximation (INLA) was used as a tool for Bayesian inference. All results were adjusted for sociodemographic variables. The results showed an association between trace contents of heavy metals and metalloids in topsoil and mortality due to tumours of the digestive system in mainland Spain. This association was observed in both sexes, something that would support the hypothesis that the incorporation of heavy metals into the trophic chain might be playing a role in the aetiology of some types of cancer. Topsoil composition and the presence of potentially toxic elements in trace concentrations might be an additional component in the aetiology of some types of cancer, and go some way to determine the ensuing geographic differences in mortality in Spain. The results support the interest of inclusion of heavy metal levels in topsoil as a hypothesis in analytical epidemiological studies using biological markers of exposure to heavy metals and metalloids.

Keywords Cancer mortality $\cdot$ Spatial data analysis . Geochemistry · Soil composition · Compositional analysis . Medical geology

\section{Introduction}

The study of the relationship between natural geological factors and health in humans and animals has been called medical geology (Selinus et al. 2013). It is a field of research with many years of tradition, which forms part of the discipline known as environmental epidemiology. Historically, it arose as a result of the observation of geographical differences in disease distribution 
(Peeters 1987). Medical geology is currently undergoing a qualitative change due to the interaction among scientist from different disciplines, and in research opportunities to better understand how the natural environment impacts human health (Centeno et al. 2013).

The Spanish Geological and Mining Institute (Instituto Geológico and Minero de España/IGME) recently published the "Geochemical Atlas of Spain", the first geochemical study of surface materials to cover the entire country (Locutura et al. 2012), and the study reported here is fruit of the collaboration among cancer epidemiologists (López-Abente et al. 2007) (López-Abente et al. 2014) and geochemists from IGME (Locutura et al. 2012).

The presence of toxic metals in soil per se, and in soil impacted human activities is a major concern for both human health and ecotoxicology (Ranville 2005). Exposure to arsenic and heavy metals is associated with various types of cancer, but there is far less information on the health effects of low-dose chronic exposure to many trace metals (Naujokas et al. 2013) (Centeno et al. 2013). Studies on the health effects of metals in topsoil belong to this latter category.

Data drawn from geochemical soil studies tend to be recorded in milligram per kilogram or parts per million (ppm) and have been called compositional data (Aitchison 1994) or closed number systems (Reimann et al. 2011). Data of this type are characterised by vectors whose components are the part of a whole and are not therefore independent (e.g. their sum is a constant). For instance, in geochemical soil studies, this could induce negative correlations or no correlations in variables one would logically expect to be positively correlated. The usual approach in the compositional analysis is to remove the closure effects in data points, using different transformations, (viz, logratio analysis) (Aitchison 1982) based on relative magnitudes. Because the absolute magnitudes of compositional variables are ratios to a common sum, Aitchison proposed to use relative magnitudes by calculating the ratio of each compositional variable compared to a single variable that functions as a constant divisor (Xie et al. 2003). Multivariate analysis is applied to logratios instead of the original data.

In this context, the aim of this study was to assess the possible association between heavy metal and metalloid levels in topsoil and mortality due to 27 different tumour types in 7917 Spanish mainland towns, with the resulting spatial relative risk (RR) estimates being adjusted for sociodemographic variables as possible confounders.

\section{Material and methods}

\section{Mortality data and soil sampling and metal analysis}

A detailed description of the data of mortality and taken soil samples can be found in a previously published study (Nuñez et al. 2016). Briefly, mortality data (observed and expected cases) for each of the 8077 (7917 mainland) Spanish towns were drawn from the records of the National Statistics Institute (NSI) for the study period (1999-2008) and computed for 27 types of malignant tumours (see Supplementary data, Table S1) with a total of 861,440 deaths due to the tumours analysed. Across the period June 2008-November 2010, a total of 21,187 residual soil samples $(13,505$ from the surface horizon and 7682 from the deeper horizon) were collected at a total of 13,505 sampling points (13,317 in mainland Spain and 188 on the Canary and Balearic islands). Residual soil is a soil belonging to the geological substratum and therefore not transported. The residual soil samples were analysed by instrumental inductively coupled plasma mass spectrometry (ICP-MS). The elements included in this analysis were Al, As, $\mathrm{Cd}, \mathrm{Cr}, \mathrm{Cu}, \mathrm{Fe}, \mathrm{Mn}, \mathrm{Ni}, \mathrm{Pb}$ and $\mathrm{Zn}$. A detailed description of the sample-collection and the chemical-analysis techniques used can be found in the Geochemical Atlas of Spain (Locutura et al. 2012). All the laboratory determinations were performed at Activation Laboratories Ltd., (Actlabs, Ontario).

Cancer mortality data are aggregated at a town area level, while the data concentrations of metals in the soil are measures taken at sampling locations across the country. In order to obtain a representative value of this concentration at the town area level, an interpolation method (ordinary kriging) for the town's centroid was used (Ribeiro and Diggle 2001) (Diggle and Ribeiro 2006).

\section{Topsoil data transformations}

For compositional data, the sum of all concentrations of the elements in each sample is almost constant or at least restricted. Then to avoid spurious correlation, the soil composition estimated at each town were transformed by centred logratio transformation (clr-transformation). The clr-transformation (Filzmoser et al. 2010) (Aitchison 1982) (Aitchison 2003) results in a multivariate observation $y=\left(y_{1}, \ldots y_{\mathrm{D}}\right)$, and is defined as:

$y=\left(\log \frac{x_{1}}{\sqrt{\prod_{i=1}^{D} x_{i}}} \ldots, \log \frac{x_{D}}{\sqrt{\prod_{i=1}^{D} x_{i}}}\right)$

Each value of a variable for each point was divided by the geometric mean of all variables for that point, and the logarithms then obtained (Reimann et al. 2011).

\section{Reduction of dimensions (factorial analysis)}

A direct consequence of the previous transformation is emerging collinearity (e.g. cadmium occurs mainly in ores with zinc and to lesser degree with lead and copper). Moreover, clrtransformation produces variables whose correlation matrix 
is singular. It is therefore difficult to conduct a regression analysis with such explanatory variables.

In order to avoid this problem, a factorial analysis was conducted to obtain independent latent factors for the clrtransformed variables (Filzmoser et al. 2010). This type of analysis provides information about the internal structure of the geochemical data, reduces data dimensionality to a few representative factors and thus seeks to summarise the multivariate information in a compact form. We performed this analysis by using robust principal factor analysis (PFA), in which 4 factors obtain a cumulative variance of over $75 \%$. For statistical analysis purposes, the factor scores for each point were extracted after rotation by the varimax method.

\section{Statistical analysis}

The association between metal concentrations in soil and cancer mortality was assessed in an ecological regression, where the response was the number of observed deaths from cancer, with expected cases as offset, and the exposure covariate were the factor scores obtained from the kriging estimate of the metal concentration in the municipal-centroid area.

Let $F_{i j}$ denote the factorial burden for each factor $(j)$ at each centroid area location $(i)$. Assume that the observed number of cases $O_{i}$ in the $I^{\text {th }}$ area is Poisson distributed, with mean $E_{i} \lambda_{i}$, where $E_{i}$ is the expected number of cases in that area and the relative risk $\lambda_{i}$ follows a log-linear model, such that:

$\log \left(\lambda_{i}\right)=\alpha+\sum_{j=1}^{4} \beta_{j} F_{i j}+\sum_{k} \delta_{k} \operatorname{Soc}_{i k}+u_{i}+v_{i}$

where $\alpha$ is an intercept, $\beta_{j}$ is the coefficient for the exposure covariates $F_{i j}$ obtained from the factorial analysis, $S_{o c} c_{i k}$ sociodemographic indicators, $v_{i}$ are unstructured normal residuals and $u_{i}$ are spatially structured effects which follow an intrinsic conditional autoregressive model, namely, the Besag, York and Mollié model (BYM) (Besag et al. 1991). Inference for the parameters of interest is made in a Bayesian framework, and prior distributions are specified for all parameters.

The sociodemographic indicators $\left(\operatorname{Soc}_{i k}\right)$ were obtained from the 1991 census and considered for their availability at the city level and potential explanatory ability vis-à-vis certain geographic mortality patterns (López-Abente et al. 2006). These indicators were as follows: population size (categorised into three levels 0-2000 [rural zone], 2000-10,000 [semi-urban zone], and over 10,000 inhabitants [urban zone]); percentages of illiteracy, farmers and unemployment; average number of persons per household and mean income.

All the analysis and graphic representations has been effected with the program $\mathrm{R}$ and their different libraries in each case, the kriging with geoR (Ribeiro and Diggle 2001) and factorial analysis with StatDA (Reimann et al. 2011). Integrated Nested Laplace Approximations (INLAs) (Rue et al. 2009) were used as a tool for Bayesian inference. For this purpose, we used R-INLA (Rue and Martino 2010), with the option of "Gaussian" estimation of the parameters. A total of 7917 Spanish mainland towns were included, and the spatial data on municipal contiguities were obtained by processing the official NSI maps.

\section{Results}

The mean topsoil concentrations in towns in the study area are shown in Table 1. Soil levels ranged from 0.01 to $>5000 \mathrm{mg}$ $\mathrm{kg}^{-1}$ for cadmium and lead, and from 0.10 to $>2000 \mathrm{mg} \mathrm{kg}^{-1}$ for arsenic, nickel and lead. The interpolation procedure reduced the range of determinations in both elements, basically influencing the extreme values.

Figure 1 shows the factor loading plots for the clrtransformed four-factor models (PFA and varimax rotation). The position of the element names in the plot reflects the loading of that element on the different factors. In addition, the percentages at the top of the plots display the cumulative explained percentage of total variability. The scale on the horizontal axis is in accordance with the relative amount of variability explained by each individual factor (Filzmoser et al. 2009). This figure gives an idea of the significance/ composition of each factor. The comments refer to items with factor scores $\geq|0.4|$. Factor F1 was defined by a combination of negative loadings of $\mathrm{Zn}, \mathrm{Al}, \mathrm{Mn}$ and positive loadings of $\mathrm{Ni}$ and $\mathrm{Cu}$. Factor F2 was dominated by negative loadings of $\mathrm{Cd}$ and positive loadings of $\mathrm{Fe}$ and $\mathrm{Cr}$. Factor $\mathrm{F} 3$ increased with the $\mathrm{Pb} / \mathrm{Ni}$ ratio. Factor $\mathrm{F} 4$ decreased when the concentration of As increased, whereas the rest of the composition remained almost constant.

Table 2 shows the relative risks (RRs) with 95\% credibility intervals, which do not include unity (statistically significant) of the four score loads for the tumours analysed, by sex. The table shows the associations shared by men and women, with the factors marked in bold. The most evident associations were those displayed by tumours of the digestive system. While the RRs shown were somewhat difficult to interpret due to the transformations, they nonetheless indicate that an increase in factor scores amounts to an increase in mortality. Associations were also observed in the case of haematological tumours.

Digestive system tumours displayed the greatest number of associations with factors. The single factor most frequently positively associated with cancer mortality was factor F3 $(\mathrm{Pb})$. It is also important to consider the results of negative associations shown in Table 3. Thus, in the case of factor F4, characterised by a very low As concentration, related mortality was lower than expected for the following tumours: buccal cavity and pharynx; oesophagus; stomach; colorectal; pancreas; prostate; kidney; brain and NHL (see supplementary data). 
Table 1 Study of topsoil metal levels ( $\mathrm{mg} \mathrm{kg}^{-1}$ ), with interpolation by towns
Fig. 1 Factor loading plots for the centred logratio-transformed (clr-transformed) four-factor models (PFA and varimax rotation)

\begin{tabular}{|c|c|c|c|c|c|c|}
\hline & No. ${ }^{a}$ & Min & $\mathrm{P}(25)$ & $\mathrm{P}(50)$ & $\mathrm{P}(75)$ & Max \\
\hline \multicolumn{7}{|l|}{ All samples (13317) } \\
\hline $\mathrm{Al}$ & & 100.000 & $13,200.000$ & $19,100.000$ & $26,700.000$ & $100,000.000$ \\
\hline As & & 0.100 & 5.300 & 9.000 & 15.300 & 2510.000 \\
\hline $\mathrm{Cd}$ & & 0.010 & 0.060 & 0.100 & 0.190 & 17.400 \\
\hline $\mathrm{Cr}$ & & 0.500 & 15.600 & 23.200 & 33.800 & 2100.000 \\
\hline $\mathrm{Cu}$ & & 0.010 & 9.140 & 15.700 & 25.700 & 6150.000 \\
\hline $\mathrm{Fe}$ & & 0.010 & 1.630 & 2.420 & 3.380 & 30.700 \\
\hline $\mathrm{Mn}$ & & 1.000 & 226.000 & 384.000 & 632.000 & $>10,000.000^{\mathrm{b}}$ \\
\hline $\mathrm{Ni}$ & & 0.100 & 13.300 & 22.500 & 32.100 & 3840.000 \\
\hline $\mathrm{Pb}$ & & 0.010 & 15.300 & 21.400 & 31.300 & 9120.000 \\
\hline $\mathrm{Zn}$ & & 0.100 & 33.100 & 51.600 & 75.900 & $>10,000.000^{\mathrm{b}}$ \\
\hline Interpolation by towns & 7917 & & & & & \\
\hline $\mathrm{Al}$ & & 3629.000 & $16,150.000$ & $19,150.000$ & $23,450.000$ & $62,360.000$ \\
\hline As & & 1.000 & 9.106 & 12.810 & 16.970 & 99.374 \\
\hline $\mathrm{Cd}$ & & 0.016 & 0.099 & 0.151 & 0.231 & 1.908 \\
\hline $\mathrm{Cr}$ & & 6.458 & 20.230 & 24.987 & 29.860 & 243.687 \\
\hline $\mathrm{Cu}$ & & 2.676 & 13.230 & 17.774 & 23.450 & 189.414 \\
\hline $\mathrm{Fe}$ & & 0.325 & 1.860 & 2.351 & 2.881 & 6.637 \\
\hline $\mathrm{Mn}$ & & 55.033 & 406.100 & 510.716 & 628.500 & 2272.732 \\
\hline $\mathrm{Ni}$ & & 4.809 & 19.090 & 25.213 & 30.180 & 502.426 \\
\hline $\mathrm{Pb}$ & & 6.499 & 18.270 & 22.612 & 28.280 & 682.033 \\
\hline $\mathrm{Zn}$ & & 12.167 & 44.000 & 56.050 & 73.460 & 457.039 \\
\hline
\end{tabular}

${ }^{\mathrm{a}}$ Number of towns

${ }^{\mathrm{b}}$ Quantification limit

FA (clr-transformed)

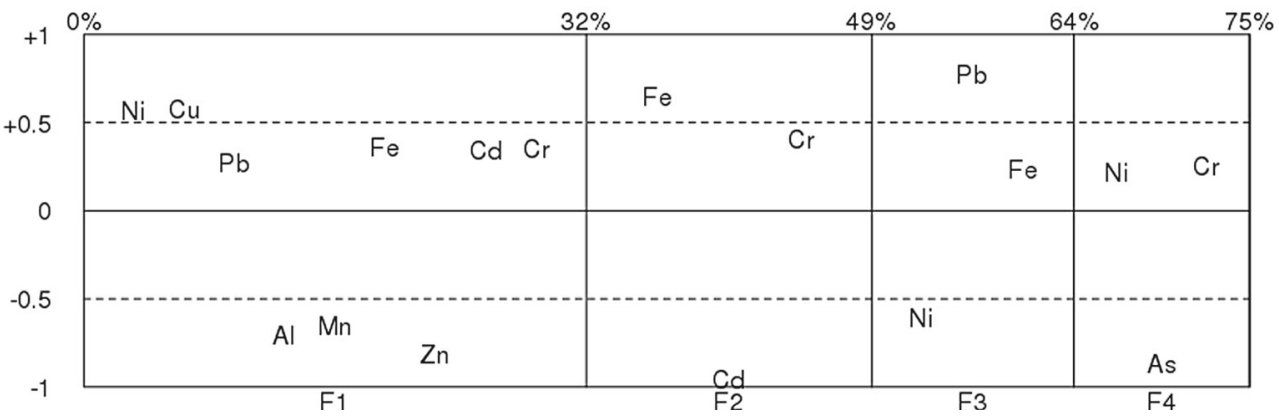

Factor loadings

\begin{tabular}{ccccc}
\hline & Factor 1 & Factor 2 & Factor 3 & Factor 4 \\
\hline $\mathrm{Ni}$ & 0.571 & & -0.610 & 0.216 \\
$\mathrm{Cu}$ & 0.575 & 0.153 & & 0.153 \\
$\mathrm{~Pb}$ & 0.272 & & $\mathbf{0 . 7 7 6}$ & \\
$\mathrm{Al}$ & $\mathbf{- 0 . 7 0 9}$ & & & \\
$\mathrm{Mn}$ & $\mathbf{- 0 . 6 5 1}$ & & & 0.150 \\
$\mathrm{Fe}$ & 0.363 & 0.647 & 0.237 & \\
$\mathrm{Zn}$ & $\mathbf{- 0 . 8 1 2}$ & & & 0.142 \\
$\mathrm{Cd}$ & 0.343 & $-\mathbf{0 . 9 5 8}$ & & \\
$\mathrm{As}$ & 0.139 & & & $\mathbf{0 . 8 6 9}$ \\
$\mathrm{Cr}$ & 0.349 & 0.407 & -0.190 & 0.275 \\
\hline
\end{tabular}


Table 2 Estimates of the effect (RR $>1$ and $95 \%$ credibility interval (CI)) of factors corresponding to score loads from PFA, on mortality due to different tumour types, by sex. The table shows the results of the clrtransformed data analysis zadjusted for sociodemographic variables

\begin{tabular}{|c|c|c|c|c|c|c|c|}
\hline \multirow[t]{2}{*}{ Cancer site } & \multirow[t]{2}{*}{ Factors } & \multicolumn{3}{|l|}{ Men } & \multicolumn{3}{|c|}{ Women } \\
\hline & & $\mathrm{RR}$ & $95 \%$ & $\mathrm{CI}$ & $\mathrm{RR}$ & $95 \%$ & $\mathrm{CI}$ \\
\hline Buccal cavity and pharynx & F1 & 1.031 & 1.009 & 1.054 & 1.059 & 1.023 & 1.095 \\
\hline Lung & F1 & 1.085 & 1.018 & 1.155 & 1.153 & 1.072 & 1.240 \\
\hline NHL & $\mathrm{F} 1$ & 1.010 & 0.987 & 1.032 & 1.022 & 1.000 & 1.044 \\
\hline Leukaemias & $\mathrm{F} 1$ & 1.023 & 1.006 & 1.041 & 0.998 & 0.979 & 1.017 \\
\hline Oesophagus & $\mathrm{F} 2$ & 0.984 & 0.960 & 1.009 & 1.063 & 1.008 & 1.120 \\
\hline Stomach & F2 & 1.051 & 1.032 & 1.069 & 1.043 & 1.022 & 1.064 \\
\hline Colorectal & F2 & 1.015 & 1.003 & 1.027 & 1.018 & 1.005 & 1.030 \\
\hline Lung & F2 & 1.026 & 1.015 & 1.037 & 1.033 & 1.012 & 1.055 \\
\hline Skin & F2 & 1.005 & 0.956 & 1.056 & 1.084 & 1.029 & 1.142 \\
\hline NHL & F2 & 1.027 & 1.001 & 1.054 & 1.038 & 1.012 & 1.065 \\
\hline Buccal cavity and pharynx & F3 & 1.056 & 1.039 & 1.072 & 1.021 & 0.996 & 1.046 \\
\hline Oesophagus & F3 & 1.063 & 1.046 & 1.081 & 1.064 & 1.030 & 1.099 \\
\hline Stomach & F3 & 1.013 & 1.000 & 1.025 & 1.001 & 0.988 & 1.015 \\
\hline Colorectal & F3 & 1.008 & 1.000 & 1.016 & 0.986 & 0.978 & 0.994 \\
\hline Liver & F3 & 1.053 & 1.033 & 1.072 & 1.057 & 1.028 & 1.087 \\
\hline Nasal cavity & F3 & 1.108 & 1.043 & 1.178 & 1.009 & 0.931 & 1.094 \\
\hline Pancreas & F3 & 1.020 & 1.008 & 1.032 & 1.015 & 1.003 & 1.028 \\
\hline Lung & F3 & 1.016 & 1.008 & 1.024 & 1.023 & 1.010 & 1.037 \\
\hline Pleura & F3 & 1.059 & 1.010 & 1.109 & 1.028 & 0.976 & 1.082 \\
\hline Connective tissue & F3 & 1.036 & 1.007 & 1.067 & 1.019 & 0.983 & 1.057 \\
\hline NHL & F3 & 1.027 & 1.009 & 1.044 & 1.021 & 1.005 & 1.038 \\
\hline Leukaemia & F3 & 1.020 & 1.007 & 1.033 & 1.003 & 0.990 & 1.017 \\
\hline Liver & $\mathrm{F} 4$ & 1.001 & 0.981 & 1.022 & 1.065 & 1.033 & 1.099 \\
\hline Gallbladder & F4 & 1.031 & 1.002 & 1.061 & 1.049 & 1.027 & 1.072 \\
\hline Pleura & $\mathrm{F} 4$ & 1.030 & 0.973 & 1.090 & 1.101 & 1.024 & 1.182 \\
\hline Breast & $\mathrm{F} 4$ & & & & 1.014 & 1.005 & 1.024 \\
\hline
\end{tabular}

F1: $(-\mathrm{Zn}-\mathrm{Al}-\mathrm{Mn}) \mathrm{Ni} \mathrm{Cu} \mathrm{Fe} \mathrm{Cd} \mathrm{Cr}$

F2: $(-\mathrm{Cd}) \mathrm{Fe} \mathrm{Cr}$

$\mathrm{F} 3: \mathrm{Pb}(-\mathrm{Ni})$

F4: $(-\mathrm{As})$

Figure 2 shows maps that plot the municipal distribution of factor scores, with F1 displaying a diffuse spatial pattern marked by a greater presence in inland towns, F2 mostly representing $\mathrm{Cd}$ levels, $\mathrm{F} 3$ similarly depicting $\mathrm{Pb}$ levels, and F4 being characterised by negative factor scores for As.

\section{Discussion}

The results indicate a statistical association between low heavy metal and metalloid content in topsoil and mortality due to tumours of the digestive system in mainland Spain. This association was shown in both sexes, a finding that would support the hypothesis that the incorporation of heavy metals into the trophic chain might be playing a role in the aetiology of some types of cancer. Note should also be taken of the results pertaining to lung and pleural cancer. Similarly, an association with haematological tumours was also in evidence.

With regard to the statistical associations found, F3, characterised by a higher lead versus nickel content, was the single factor that showed the highest number of statistical associations with different tumour locations. Hence, mortality was correlated with this factor in virtually all sites of cancer of the digestive system in men, and in cancer of the oesophagus, liver, pancreas, lung and NHL in both sexes. Some of these associations have been observed by other types of studies in the case of cancer of the stomach (Zhao et al. 2014) and pancreas (Amaral et al. 2012). The IARC classifies inorganic lead compounds as probably carcinogenic to humans (Group 2A) and lead exposure is known to increase the risk of lung, stomach and bladder cancer (IARC Working Group 2006).

A result of considerable interest was that pertaining to As. Factor F4 was fundamentally characterised by low content in 
Table 3 Summary of estimates of the protective effect $(R R<1)$ of factors corresponding to score loads from PFA, on mortality due to different tumour types, by sex. The table shows the results of the clr-transformed data adjusted for sociodemographic variables
Fig. 2 Municipal distribution of score loads from principal factor analysis of heavy metal concentrations in topsoil in mainland Spain. Factorial analysis performed with clrtransformed data

\begin{tabular}{|c|c|c|c|c|c|c|c|}
\hline \multirow[t]{2}{*}{ Cancer site } & \multirow[t]{2}{*}{ Factors } & \multicolumn{3}{|l|}{ Men } & \multicolumn{3}{|c|}{ Women } \\
\hline & & $\mathrm{RR}$ & $95 \%$ & $\mathrm{CI}$ & $\mathrm{RR}$ & $95 \%$ & $\mathrm{CI}$ \\
\hline Stomach & F1 & 0.966 & 0.951 & 0.982 & 0.948 & 0.932 & 0.965 \\
\hline Skin & $\mathrm{F} 1$ & 0.959 & 0.917 & 1.002 & 0.940 & 0.898 & 0.984 \\
\hline Melanoma & $\mathrm{F} 2$ & 0.933 & 0.899 & 0.969 & 0.972 & 0.933 & 1.013 \\
\hline Uterus & F2 & & & & 0.977 & 0.957 & 0.997 \\
\hline Bladder & $\mathrm{F} 2$ & 0.976 & 0.960 & 0.993 & 0.979 & 0.952 & 1.006 \\
\hline Myeloma & $\mathrm{F} 2$ & 0.986 & 0.960 & 1.013 & 0.948 & 0.923 & 0.974 \\
\hline Bone & F3 & 1.001 & 0.967 & 1.036 & 0.948 & 0.911 & 0.985 \\
\hline Breast & F3 & & & & 0.987 & 0.978 & 0.995 \\
\hline Ovarian & F3 & & & & 0.980 & 0.968 & 0.992 \\
\hline Buccal cavity and pharynx & $\mathrm{F} 4$ & 0.951 & 0.934 & 0.967 & 0.993 & 0.963 & 1.023 \\
\hline Oesophagus & $\mathrm{F} 4$ & 0.970 & 0.952 & 0.988 & 1.011 & 0.972 & 1.052 \\
\hline Stomach & F4 & 0.955 & 0.943 & 0.968 & 0.951 & 0.937 & 0.966 \\
\hline Colorectal & F4 & 0.977 & 0.968 & 0.986 & 0.990 & 0.981 & 0.999 \\
\hline Pancreas & F4 & 0.972 & 0.959 & 0.985 & 0.987 & 0.973 & 1.001 \\
\hline Nasal cavity & $\mathrm{F} 4$ & 0.875 & 0.812 & 0.943 & 0.934 & 0.838 & 1.041 \\
\hline Lung & F4 & 0.990 & 0.982 & 0.998 & 0.983 & 0.968 & 0.998 \\
\hline Skin & F4 & 0.980 & 0.944 & 1.018 & 0.939 & 0.903 & 0.977 \\
\hline Prostate & F4 & 0.979 & 0.969 & 0.988 & & & \\
\hline Kidney & $\mathrm{F} 4$ & 0.977 & 0.959 & 0.995 & 1.011 & 0.987 & 1.035 \\
\hline Brain & $\mathrm{F} 4$ & 0.969 & 0.952 & 0.985 & 0.980 & 0.961 & 1.000 \\
\hline NHL & F4 & 0.975 & 0.957 & 0.994 & 0.983 & 0.964 & 1.001 \\
\hline
\end{tabular}

F1: $(-\mathrm{Zn}-\mathrm{Al}-\mathrm{Mn}) \mathrm{Ni} \mathrm{Cu} \mathrm{Fe} \mathrm{Cd} \mathrm{Cr}$

F2: (-Cd) $\mathrm{Fe} \mathrm{Cr}$

$\mathrm{F} 3: \mathrm{Pb}(-\mathrm{Ni})$

F4: (-As)

Factor 1 ZnAIMn

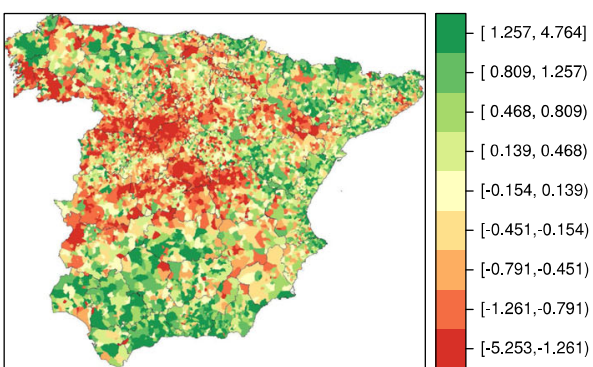

Factor $3 \sim \mathrm{Pb}$

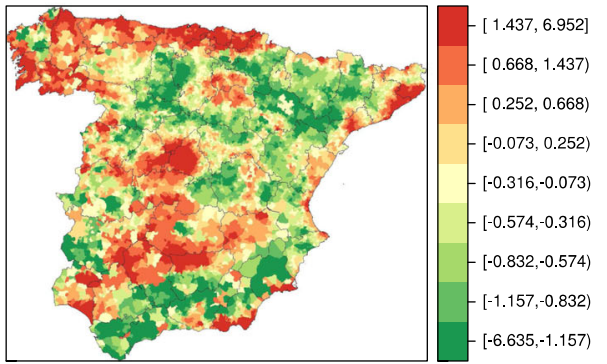

Factor $2 \sim \mathrm{Cd}$

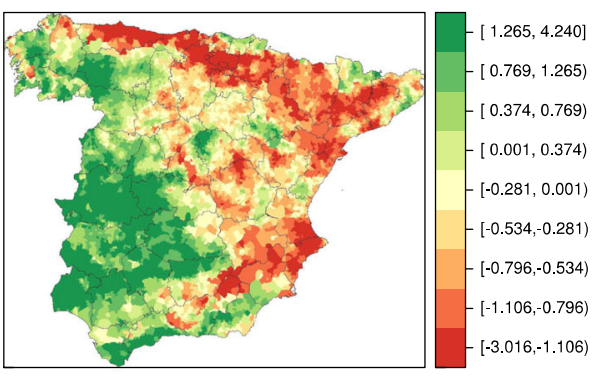

Factor 4 As

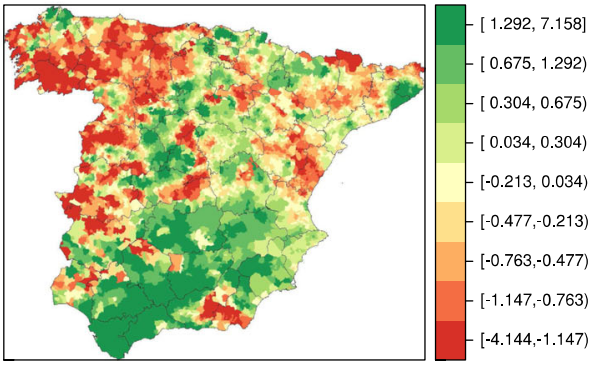


arsenic with respect to other metals (As factor loadings of -0.87 ). Cancers that displayed RRs which were less than 1 and were statistically significant for factor F4, in both sexes, were those of buccal cavity and pharynx, oesophagus, stomach, colorectal, pancreas, lung, prostate, kidney, brain and NHL. The converse of these results would support the possible role of topsoil As in cancer, as previously reported elsewhere (Nuñez et al. 2016).

With regard to the RRs magnitude, the clr-transformations of data and the use of factorial loadings, make it difficult to measure the impact on the population. The risk of the population derived from the composition of the soil is probably very low, but it is surprising to find the displayed spatial dependence.

The concentration of heavy metals in soil determines their presence in animal tissue (López Alonso et al. 2002). The small number of studies means that there is very little epidemiological evidence of the association between arsenic topsoil levels and frequency of cancer. However, heavy metal and arsenic topsoil concentrations serve as an indicator of longterm exposure to these elements (Tchounwou et al. 2012). Exposure to arsenic and inorganic arsenic compounds cause, with sufficient evidence, lung, skin and urinary bladder cancers and with limited evidence kidney, liver and prostate cancer. Cadmium and cadmium compounds exposure is a cause of lung cancer and possible of prostate and kidney cancers. Chromium (VI) compounds are a cause of lung cancer and possibly nasal cavity and paranasal sinuses cancers. Exposure to nickel compounds is a cause of lung, nasal cavity and paranasal sinuses cancers. The biological mechanisms involved are oxidative DNA damage, genomic instability, aneuploidy, gene amplification, epigenetic effects, DNA-repair inhibition leading to mutagenesis among others (Straif et al. 2009).

It is of interest to view the results from the perspective of each type of cancer and find that the tumours which displayed most associations with the respective factors were stomach and lung cancer (see supplementary material): while stomach cancer was associated with all four factors, i.e. F1, F2 and F4 in both sexes and F3 in men only, lung cancer was associated with F2, F3 and F4 in both sexes.

The risk resulting from chronic exposure to a mixture of potentially toxic items in topsoil confronts one with the problem of choosing a paradigm different to the prevailing one of "single chemical as carcinogen" (Miller et al. 2016). Regulatory measures governing tolerable/permitted-to-toxic environmental levels are based on this paradigm, and its reconsideration has thus to be based on a process of proper evaluation/testing which highlights the importance of mixtures of toxic elements.

The mechanism underlying the results obtained for tumours of the digestive system and haematological tumours might be the incorporation of these elements into trophic chain and drinking water, since diet is the main source of exposure to potentially toxic elements (Delgado-Andrade et al. 2003) (Burló et al. 2012).

Metals of the soil are hardly degradable by microbes of the soil and its extension to the food chain poses a threatens potential for the health human ( $\mathrm{Li}$ et al. 2014). Human beings could be exposed to heavy metals from soils via several pathways, ingestion (particles, diet and water), dermal contact and inhalation (Abrahams 2002) (Liu et al. 2013).

One limitation of this type of studies lies in their lack of speciation of the element. Speciation determines the potential bioaccessibility and bioavailability of the element. Arsenic, for example, is in the environment such as organic and inorganic compounds and the problem of toxicity is with inorganic compounds (Kamel Boulos and Le Blond 2016). The two forms of inorganic arsenic, reduced (trivalent As (III)) and oxidised (pentavalent As (V)), can be absorbed, and accumulated in tissues and body fluids and are the most common oxidation states. Trivalent are more toxic than pentavalent inorganic arsenic species, and while pentavalent arsenicals may be more likely to occur in natural environments, following absorption into the body, pentavalent arsenicals may be reduced to methylated trivalent metabolites, and the overall toxicity is dependent on the rate of methylation of the As (III) formed (Vahter and Concha 2001).

Our results raise the importance of the compositional nature of data in this type of analysis, e.g. the regression analysis based on clr-transformation allowed us to assess the relationship with different mixtures/cocktails of metals (relative proportion of each element in the factor) (Aitchison 2003) (Reimann et al. 2011) (van den Boogaart and TolosanaDelgado 2013). The absolute magnitudes of compositional variables are ratios to a common sum (in our case $1 \mathrm{Kg}$ ). Thus, no single variable is free to vary separately from the rest of the composition. However, the relative magnitudes are the ratio of each compositional variable compared to a single variable and remove the closure effect. The centred logratio (clr) is such a transformation and provide a one-to-one relationship from the simplex to the standard Euclidean space with good geometric properties. The direct application of multivariate statistical methods to raw compositional data can lead to improper results. For example, the problem of so-called spurious correlations occurs, namely that one can obtain different results of correlation analysis, depending on whether the whole composition or only a subcomposition is taken (Filzmoser et al. 2009). However, these are methods which were developed in geochemistry and which are only just beginning to become known in the epidemiological sphere. While examples of compositional data analysis were indeed found in epidemiology, and specifically in nutrition and microbiota studies, it is nonetheless acknowledged that there has been insufficient methodological development in this area (Leite 2014) (Tsilimigras and Fodor 2016). 
Spatial models were used in the analysis, thus making it possible to estimate the overall influence of topsoil trace components on mortality. Furthermore, the estimates of RR of death were adjusted for various sociodemographic variables. Generally speaking, this type of analysis tends to be somewhat conservative (relatively insensitive), and revealing associations proves difficult (Richardson et al. 2004).

However, we have to be very careful in the interpretation of these results since the statistical associations, although they seem plausible, do not mean a direct biological correlate. The results support the interest of inclusion of heavy metal levels in topsoil as a hypothesis in analytical epidemiological studies of cancer using biological markers of exposure to heavy metals and metalloids.

\section{Conclusions}

The results of our study show a statistical association between the trace contents of heavy metals and metalloids in topsoil and mortality due to tumours of the digestive system in mainland Spain. This association is observed in both sexes, a finding which would support the hypothesis that the incorporation of heavy metals into the trophic chain might be playing a role in the aetiology of some types of cancer. Similarly, noteworthy are the results pertaining to lung cancer and pleural cancer and the association with haematological tumours. Accordingly, the presence of potentially toxic elements in trace concentrations in topsoil composition might be an additional component in the aetiology of some types of cancer, and go some way to determine the ensuing geographical differences in Spain. The results support the interest of inclusion of heavy metal levels in topsoil as a hypothesis in analytical epidemiological studies using biological markers of exposure to heavy metals and metalloids.

Acknowledgements The study was partially supported by research grants from the Carlos III Institute of Health (PI4CIII/50) and Spanish Health Research Fund (FIS PI11/00871 and FIS CP11/00112). Mortality data were supplied by the Spanish National Statistics Institute in accordance with a specific confidentiality protocol.

Open Access This article is distributed under the terms of the Creative Commons Attribution 4.0 International License (http:// creativecommons.org/licenses/by/4.0/), which permits unrestricted use, distribution, and reproduction in any medium, provided you give appropriate credit to the original author(s) and the source, provide a link to the Creative Commons license, and indicate if changes were made.

\section{References}

Abrahams PW (2002) Soils: their implications to human health. Sci Total Environ 291:1-32
Aitchison J (1994) Principles of compositional data analysis. In: Multivariate analysis and its applications. Institute of Mathematical Statistics Lecture Notes, Institute of Mathematical Statistics, pp 7381

Aitchison J (1982) The statistical analysis of compositional data. J R Stat Soc 44:139-177

Aitchison J (2003) The statistical analysis of compositional data. The Blackburn Press, USA

Amaral AFS, Porta M, Silverman DT et al (2012) Pancreatic cancer risk and levels of trace elements. Gut 61:1583-1588. doi:10.1136/gutjnl2011-301086

Besag J, York J, Mollié A (1991) Bayesian image restoration with two applications in spatial statistcs. Ann Inst Stat Math 43:1-59

Burló F, Ramírez-Gandolfo A, Signes-Pastor AJ et al (2012) Arsenic contents in Spanish infant rice, pureed infant foods, and rice. $\mathrm{J}$ Food Sci 77:T15-T19. doi:10.1111/j.1750-3841.2011.02502.x

Centeno J, Mullick F, Ishak K et al (2013) Environmental pathology. Essentials of Medical Geology, Revised Edition. Springer, Dordrecht, The Netherlands, In

Delgado-Andrade C, Navarro M, López H, López MC (2003) Determination of total arsenic levels by hydride generation atomic absorption spectrometry in foods from south-east Spain: estimation of daily dietary intake. Food Addit Contam 20:923-932. doi:10.1080/02652030310001594450

Diggle P, Ribeiro P (2006) Model-based Geostatistics. Springer, New York

Filzmoser P, Hron K, Reimann C (2010) The bivariate statistical analysis of environmental (compositional) data. Sci Total Environ 408:4230 4238. doi:10.1016/j.scitotenv.2010.05.011

Filzmoser P, Hron K, Reimann C, Garrett R (2009) Robust factor analysis for compositional data. Comput Geosci 35:1854-1861

IARC Working Group, Carcinogenic Risks to Humans, IARC Working Group on the Evaluation of (2006) Inorganic and organic lead compounds. IARC, Lyon, France

Kamel Boulos MN, Le Blond J (2016) On the road to personalised and precision geomedicine: medical geology and a renewed call for interdisciplinarity. Int J Health Geogr 15:5. doi:10.1186/s12942-0160033-0

Leite MLC (2014) Applying compositional data methodology to nutritional epidemiology. Stat Methods Med Res. doi:10.1177 /0962280214560047

Li Y, Wang H, Wang H et al (2014) Heavy metal pollution in vegetables grown in the vicinity of a multi-metal mining area in Gejiu, China: total concentrations, speciation analysis, and health risk. Environ Sci Pollut Res Int 21:12569-12582. doi:10.1007/s11356-014-3188-x

Liu X, Song Q, Tang Y et al (2013) Human health risk assessment of heavy metals in soil-vegetable system: a multi-medium analysis. Sci Total Environ 463-464:530-540. doi:10.1016/j.scitotenv.2013.06.064

Locutura J, Bel-Lan A, Garcia Cortés A, Martínez Romero S (2012) Atlas geoquímico de España. Instituto Geológico y Minero de España, Madrid

López Alonso M, Benedito JL, Miranda M et al (2002) Cattle as biomonitors of soil arsenic, copper, and zinc concentrations in Galicia (NW Spain). Arch Environ Contam Toxicol 43:103-108. doi:10.1007/s00244-002-1168-5

López-Abente G, Aragonés N, Pérez-Gómez B et al (2014) Time trends in municipal distribution patterns of cancer mortality in Spain. BMC Cancer 14:535. doi:10.1186/1471-2407-14-535

López-Abente G, Aragonés N, Ramis R et al (2006) Municipal distribution of bladder cancer mortality in Spain: possible role of mining and industry. BMC Public Health 6:17-17. doi:10.1186/1471-2458-6-17

López-Abente G, Ramis R, Pollán M et al (2007) Atlas municipal de mortalidad por cáncer en España 1989-1998. ISCIII, Madrid, Spain

Miller MF, Goodson WH, Manjili MH et al (2016) Low-dose mixture hypothesis of carcinogenesis. Scientific Underpinnings and 
Research Recommendations. Environ Health Perspect, Workshop. doi:10.1289/EHP411

Naujokas MF, Anderson B, Ahsan H et al (2013) The broad scope of health effects from chronic arsenic exposure: update on a worldwide public health problem. Environ Health Perspect 121:295-302. doi:10.1289/ehp. 1205875

Nuñez O, Fernández-Navarro P, Martín-Méndez I et al (2016) Arsenic and chromium topsoil levels and cancer mortality in Spain. Environ Sci Pollut Res. doi:10.1007/s11356-016-6806-y

Peeters EG (1987) The possible influence of the components of the soil and the lithosphere on the development and growth of neoplasms. Experientia 43:74-81

Ranville J (2005) Evaluating the influence of soil geochemical characteristics on metal bioavailability. U.S. Geological Survey, Mineral Resources Program

Reimann C, Filzmoser P, Garrett R, Dutter R (2011) Statistical data analysis explained: applied environmental statistics with R. Wiley, Chishester, England

Ribeiro P, Diggle P (2001) geoR: a package for geostatistical analysis. RNEWS 1:15-18

Richardson S, Thomson A, Best N, Elliott P (2004) Interpreting posterior relative risk estimates in disease-mapping studies. Environ Health Perspect 112:1016-1025

Rue H, Martino S (2010) The R-INLA project. http://www.r-inla.org/. Accessed 10 Aug 2010

Rue H, Martino S, Chopin N (2009) Approximate Bayesian inference for latent Gaussian models by using integrated nested Laplace approximations. J R Stat Soc Ser B 71:319-392. doi:10.1111 jj.1467-9868.2008.00700.x

Selinus O, Alloway BJ, Centeno J, et al. (2013) Essentials of Medical Geology: Impacts of the Natural Environment on Public Health. Springer, Dordrecht, The Netherlands

Straif K, Benbrahim-Tallaa L, Baan R et al (2009) A review of human carcinogens - part C: metals, arsenic, dusts, and fibres. Lancet Oncol 10:453-454

Tchounwou PB, Yedjou CG, Patlolla AK, Sutton DJ (2012) Heavy metals toxicity and the environment. EXS 101:133-164. doi:10.1007/9783-7643-8340-4_6

Tsilimigras MCB, Fodor AA (2016) Compositional data analysis of the microbiome: fundamentals, tools, and challenges. Ann Epidemiol 26:330-335. doi:10.1016/j.annepidem.2016.03.002

Vahter M, Concha G (2001) Role of metabolism in arsenic toxicity. Pharmacol Toxicol 89:1-5

van den Boogaart KG, Tolosana-Delgado R (2013) Analyzing Compositional Data with R. Springer, Heidelberg

Xie Y, Last GV, Murray CJ, Mackley R (2003) Mineralogical and BulkRock Geochemical Signatures of Ringold and Hanford Formation Sediments. Pacific Northwest National Laboratory, Richland, Washington

Zhao Q, Wang Y, Cao Y et al (2014) Potential health risks of heavy metals in cultivated topsoil and grain, including correlations with human primary liver, lung and gastric cancer, in Anhui province, Eastern China. Sci Total Environ 470-471:340-347. doi:10.1016/j. scitotenv.2013.09.086 